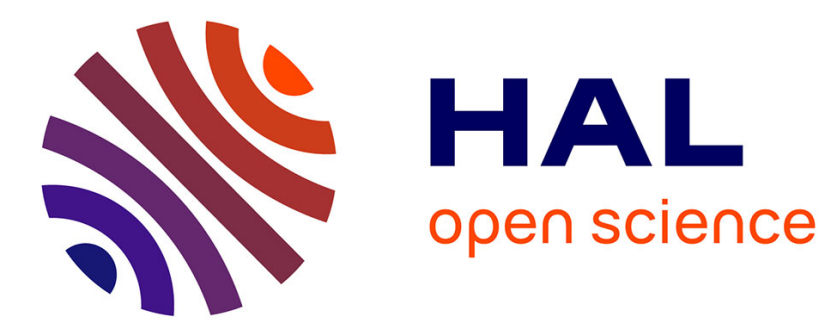

\title{
Rogue waves and extreme events in nonlinear ultrafast optics
}

\author{
J.M. Dudley, G. Genty, F. Dias
}

\section{To cite this version:}

J.M. Dudley, G. Genty, F. Dias. Rogue waves and extreme events in nonlinear ultrafast optics. IEEE Photonics Society annual Meeting, Oct 2009, Antalya, Turkey. 10.1109/LEOS.2009.5343299 . hal00480700

\section{HAL Id: hal-00480700 https://hal.science/hal-00480700}

Submitted on 23 Apr 2021

HAL is a multi-disciplinary open access archive for the deposit and dissemination of scientific research documents, whether they are published or not. The documents may come from teaching and research institutions in France or abroad, or from public or private research centers.
L'archive ouverte pluridisciplinaire HAL, est destinée au dépôt et à la diffusion de documents scientifiques de niveau recherche, publiés ou non, émanant des établissements d'enseignement et de recherche français ou étrangers, des laboratoires publics ou privés. 


\title{
Rogue Waves and Extreme Events in Nonlinear Ultrafast Optics
}

\author{
J. M. Dudley \\ Institut FEMTO-ST, Département d'Optique P. M. Duffieux, Université de Franche-Comté, \\ 25030 Besançon, France \\ john.dudley@univ-fcomte.fr \\ G. Genty \\ Optics Laboratory, Department of Physics, Tampere University of Technology, FIN-33101 \\ Tampere, Finland, \\ F. Dias \\ Centre de Mathématiques et de Leurs Applications, ENS Cachan, Cachan France
}

\begin{abstract}
We discuss recent studies of large amplitude extreme value "optical rogue wave" instabilities in ultrafast nonlinear optics. We consider how insight from these experiments can impact both directly in photonics and in leading to an improved understanding of rogue wave phenomena in hydrodynamics.
\end{abstract}

A central challenge in understanding extreme events in physics is to develop rigorous models linking the complex generation dynamics and the associated statistical behavior. A particular case of interest concerns the infamous oceanic rogue or freak waves that have been associated with many catastrophic maritime disasters [1]. Studying rogue waves under controlled conditions is intrinsically problematic, however, and the phenomenon remains a subject of intensive research. On the other hand, there are many links between wave propagation effects in optics and hydrodynamics, and the study of "rogue" instabilities in optics is therefore currently a subject of much interest. This talk will present a survey of recent experimental and theoretical studies obtained in ultrafast nonlinear optical systems, focusing both on the consequences of these instabilities in the context of optics and photonics applications, as well as discussing how these results may feed into developing an improved understanding of the wider class of rogue waves on the ocean.

The study of noise effects in nonlinear optical propagation has of course been the subject of extensive research for many years. Moreover, after the observation of supercontinuum generation in photonic crystal fibre in 2000, applications in frequency metrology motivated many detailed investigations into the means by which input pulse noise was transferred to the broadband spectrum [2]. The results obtained led to an improved understanding of the noise amplification process and the development of useful guidelines for the optimisation of supercontinuum spectra for specific applications [3]. A major development, however, occurred in 2007 with the report of Solli et al. who used ultrafast detection to perform the direct measurement of a time-series of the fluctuations of the long wavelength edge of the supercontinuum [4]. Specifically, the measurements showed that these fluctuations contain a small number of statistically-rare "rogue" events associated with a greatly enhanced spectral 
bandwidth and the generation of localized temporal solitons with greatly increased intensity. Crucially, because these experiments were performed in a regime where modulation instability (MI) plays a key role in the dynamics, an analogy was drawn with hydrodynamic rogue waves, whose origin and dynamics has also been discussed in terms of MI or, as it usually referred to in hydrodynamics, the Benjamin-Feir instability [5].

The analogy between the appearance of localized structures in optics and the rogue waves on the ocean's surface is both intriguing and attractive, as it opens up possibilities to explore the extreme value dynamics in a convenient benchtop optical environment. In addition to the proposed links with solitons suggested by Solli et al., other studies motivated from an optical context have explored possible links with nonlinear breather propagation [6] and the appearance of quasi-coherent localized structures from an unstable turbulent optical field [7-9]. The purpose of this paper will be to discuss these results that have been obtained in optics, and to consider both the similarities and the differences with oceanic rogue wave counterparts.

\section{References}

1. M. Hopkin, "Sea snapshots will map frequency of freak waves", Nature 430, 492 (2004)

2. K. L. Corwin, N. R. Newbury, J. M. Dudley, S. Coen, S. A. Diddams, K. Weber, R. S. Windeler, "Fundamental Noise Limitations to Supercontinuum Generation in Microstructure Fiber," Physical Review Letters 90, 113904:1-4 (2003).

3. J. M. Dudley, G..Genty, S. Coen "Supercontinuum Generation in Photonic Crystal Fibre," Rev. Mod. Phys. 78 1134 (2006)

4. D. R. Solli, C. Ropers, P. Koonath, and B. Jalali, “Optical rogue waves,” Nature 450, 1054 (2007)

5. V. E. Zakharov, A. I. Dyachenko, A. O. Prokofiev, "Freak waves as nonlinear stage of Stokes wave modulation instability,” E. J. Mech. B/Fluids 25677 (2006).

6. J. M. Dudley, G. Genty, and B. J. Eggleton, "Harnessing and control of optical rogue waves in supercontinuum generation," Opt. Express 16, 3644-3651 (2008) .

7. N. Akhmediev, A. Ankiewicz, M. Taki, "Waves that appear from nowhere and disappear without a trace," Phys. Lett. A 373, 675-678 (2009); N. Akhmediev, J. M. Soto-Crespo and A. Ankiewicz, "Extreme waves that appear from nowhere: on the nature of rogue waves", Phys. Lett. A, doi:10.1016/j.physleta.2009.04.023 (2009)

8. V. E. Zakharov et al., "Soliton Turbulence," JETP Letters 48, 83 (1988).

9. G. Genty et al. "Optical rogue waves and soliton turbulence in nonlinear fibre optics," Paper EF2.1 THU, Conference CLEO Europe-EQEC (2009). 